\title{
Comparison of Efficacy and Economic Value of Prandilin 25 and Humalog Mix 25 in Patients with Newly Diagnosed Type 2 Diabetes by a Continuous Glucose Monitoring System
}

\author{
Yong Luo · Xue-qin Wang • Wen-ji Ni • Bo Ding • Xiang-hong Xu • \\ Lei Ye $\cdot$ Jian-hua Ma $\cdot$ Jian Zhu (D)
}

Received: July 25, 2018 / Published online: September 22, 2018

(C) The Author(s) 2018

\begin{abstract}
Introduction: To determine the clinical efficacy and economic value of insulin lispro 25-Prandilin 25 vs. insulin lispro 25-Humalog mix 25 in treatment of newly diagnosed type 2 diabetes mellitus (T2DM) by a continuous glucose monitoring system (CGMS).

Methods: This was a single-center, randomized, case-crossover clinical trial. Participants were randomly allocated to two groups and
\end{abstract}

Yong Luo and Xue-qin Wang contributed equally as first authors.

Enhanced Digital Features To view enhanced digital features for this article, go to https://doi.org/10.6084/ m9.figshare.7035584.

Y. Luo $\cdot$ W. Ni $\cdot$ B. Ding $\cdot$ X. Xu

J. Ma $(\bowtie) \cdot$ J. Zhu $(\bowtie)$

Department of Endocrinology, Nanjing First

Hospital, Nanjing Medical University, Nanjing,

China

e-mail: majianhua@china.com

J. Zhu

e-mail: drzhujian@hotmail.com

X. Wang

Department of Endocrinology, The Second Affiliated Hospital of Nantong University, First People's Hospital of Nantong City, Nantong, China

L. Ye

National Heart Research Institute Singapore, National Heart Centre Singapore, Singapore, Singapore underwent two kinds of insulin lispro 25 treatment separated by a 1-day washout period. In total, 81 patients with newly diagnosed T2DM with hemoglobin A1c (HbA1c) above 9\% were hospitalized and randomly divided to receive Prandilin 25/Humalog mix 25 or Humalog mix 25/Prandilin 25 treatment. All participants were subjected to metformin therapy simultaneously. Glycemic control was reached after 7-8 days Prandilin 25 or Humalog mix 25 treatment; each patient received continuous glucose monitoring (CGM) for 5 consecutive days (from day 1 to day 5). On day 3 of CGM performance, Prandilin 25 treatment was switched to Humalog mix 25 treatment at the same dosage or vice versa. Parameters representing glycemic variability (GV) and postprandial glucose excursions, including 24-h mean blood glucose (24hMBG), 24-h standard deviation of blood glucose (24hSDBG), 24-h mean amplitude of glycemic excursion (24hMAGE), large amplitude of glycemic excursion (LAGE), incremental area under the curve (AUC) for different glucose levels, and postmeal relative areas under the CGM curve (AUCpp) for 1-4 h of each meal, were calculated for each patient.

Results: No significant differences were found in the 24hMAGE, 24hMBG, 24hSDBG, LAGE, mean $1-\mathrm{h}$ preprandial blood glucose and the incidence of hypoglycemia between the Prandilin 25 treatment group and Humalog mix 25 treatment group. Similarly, there were no between-treatment differences for AUC and 
time when blood glucose was below $3.9 \mathrm{mmol} / \mathrm{l}$, between $3.9 \mathrm{mmol} / \mathrm{l}$ and $10.0 \mathrm{mmol} / \mathrm{l}$, or above $10.0 \mathrm{mmol} / \mathrm{l}$. Further analysis showed the AUCpp for 1-4 h of each meal for two kinds of treatments were similar. However, the mean estimated cost of Prandilin 25 was only $85 \%$ of Humalog mix 25 in one treatment course.

Conclusion: Prandilin 25 is non-inferior in clinical efficacy compared with Humalog mix 25 . In view of the significant difference in the cost of the two kinds of insulin lispro 25, Prandilin 25 is a much more cost-effective antidiabetes drug for management of T2DM.

Trial Registration: Chinese Clinical Trial Register identifier, ChiCTR1800015829.

Keywords: CGMS; Glycemic variability; Humalog mix 25; Insulin lispro 25; Prandilin 25

\section{INTRODUCTION}

Diabetes mellitus is a complex and progressive metabolic disease that has approached epidemic proportions worldwide. According to the statistics of the International Diabetes Federation, the number of people with diabetes is expected to increase from 451 million in 2017 to 693 million by $2045,90 \%$ of whom will have type 2 diabetes mellitus (T2DM) [1]. Hyperglycemia was found to account for approximately $21 \%$ of all deaths from ischemic heart disease and $13 \%$ of all deaths from stroke in a survey across 52 countries [2]. On the other hand, the study of the global economic burden of diabetes showed that the cost of diabetes worldwide was 1.31 trillion USD or $1.8 \%$ of the global gross domestic product in 2015 and would reach 2.1 trillion USD in 2030 [3-5]. Further analyses indicated that twothirds of these total costs were direct medical costs and one third were indirect costs, such as lost productivity $[5,6]$. T2DM is thus a public health problem not only because of its effect on mortality, morbidity, and quality of life, but also its social and economic burden for the patient's family and country [7]. Therefore, more costeffective anti-diabetes drugs are urgently needed.

Insulin has been identified as the most effective glucose-lowering agent, and insulin replacement or supplement therapy is a key component of effective diabetes management over the course of the disease [8]. Nowadays, about $30-61.6 \%$ of patients with T2DM are on insulin therapy (premixed, one-third to twothirds) $[9,10]$. Compared with human premixed insulin, premixed insulin analogs can provide lower hypoglycemia risk, lower levels of postprandial glucose excursions, better adherence, improved quality of life, and higher patient satisfaction with treatment [11]. Thus, these insulin analogs have become the most common insulin formulation as anti-diabetic medication $[12,13]$.

Currently, two types of insulin lispro 25, Prandilin 25 (made by Gan \& Lee Pharmaceuticals, China) and Humalog mix 25 (made by Eli Lilly and Co., USA), are commonly used in clinical practice in China. However, it is not known whether Prandilin 25 has the same efficacy and safety profile related to the glycemic control of T2DM patients compared with its imported counterpart. Thus, we performed this randomized, open-label, case-crossover study between Prandilin 25 and Humalog mix 25 using a continuous glucose monitoring (CGM) system in newly diagnosed T2DM patients with HbA1c levels > 9\%.

\section{METHODS}

\section{Subjects}

This was a single-center, randomized, open-label, case-crossover clinical trial, which was approved by the Institutional Ethics Committee, Nanjing First Hospital, Nanjing, China. Informed consents were signed by all recruited subjects, and all procedures followed were in accordance with the Helsinki Declaration of 1964, as revised in 2013. In total, 81 newly diagnosed T2DM patients with HbAlc levels > 9.0\% were enrolled between April 2018 and June 2018. Patients were excluded if they (1) were positive for antiglutamic acid decarboxylase antibodies; (2) had severe cardiovascular diseases, such as stroke, myocardial infarction, coronary artery bypass grafting, percutaneous coronary intervention, and heart failure; (3) had 
severe infectious diseases; (4) had acute complications of diabetes on admission, such as diabetic ketoacidosis; (5) had severely impaired liver and kidney function and psychiatric disorders or were pregnant or planning to become pregnant. Patients with maturity-onset diabetes in youth and mitochondrial diabetes mellitus and with a cognitive disorder, alcoholism, or drug abuse were also excluded.

\section{Study Design}

In this randomized, crossover trial, participants were randomly allocated to two groups and underwent two trials separated by a 1-day washout period. Anti-hyperglycemic drug-naïve type 2 diabetic patients who met the criteria were admitted to the inpatient department of the hospital. After fasting, blood samples were collected for measuring FBG, insulin, C-peptide, and glucagon. Patients were randomly assigned to the Prandilin 25/Humalog mix 25 group or Humalog mix 25/Prandilin 25 group (three times a day, using the same needle, $4 \mathrm{~mm} / 32$ $\mathrm{G})$. All subjects from both groups generally took $1.5 \mathrm{~g}$ metformin per day simultaneously; if they could not tolerate the side effects of metformin, the daily dose of metformin was reduced to $1 \mathrm{~g} /$ day for each patient. Insulin doses were subsequently adjusted according to the patient's finger point blood glucose, which was monitored at seven time points: 0700, 0900, $1100,1300,1700,1900$, and 2200. The method of insulin titration in this study was based on the algorithm as described in our previous study [14]. Glycemic control (fasting capillary blood glucose was $<7.8 \mathrm{mmol} / \mathrm{l}$ and capillary blood glucose at $2 \mathrm{~h}$ after each of three meals was $<10.0 \mathrm{mmol} / \mathrm{l}$ ) was reached after a 7-8-day runin period. Patients used CGMS (Medtronic MiniMed, USA) to monitor the subcutaneous interstitial fluid glucose level for 5 consecutive days. At day 3 of CGM, the patients in the Prandilin 25/Humalog mix 25 group switched to Humalog mix 25 therapy at the same dosage, or vice verse. After admission, those subjects were instructed to maintain their usual physical activity and received the fixed energy intake at a fixed time. The total daily caloric intake of patients was $30 \mathrm{kcal} / \mathrm{kg} / \mathrm{day}$, and the ratio of carbohydrates, proteins, and fats was 55\%, 17\%, and $28 \%$, respectively.

\section{CGM}

CGM data were obtained with Medtronic Minimed CGMS Gold; this was performed as previously described [15]. The data collected from the CGMS were (1) 7 a.m. day 2 to 7 a.m. day 3 and (2) 7 a.m. day 4 to 7 a.m. day 5. The following parameters were calculated, including the mean amplitude of glycemic excursion of blood glucose every $24 \mathrm{~h}$ ( $24 \mathrm{hMAGE}), 24-\mathrm{h}$ mean blood glucose (24hMBG), standard deviation of 24-h blood glucose (24hSDBG), large amplitude of glycemic excursion (LAGE), glucose coefficient of variation $(\mathrm{CV})$, glucose area under the curve (AUC) below $3.9 \mathrm{mmol} / \mathrm{l}$, between $3.9 \mathrm{mmol} / \mathrm{l}$ and $10.0 \mathrm{mmol} / \mathrm{l}$, and above $10.0 \mathrm{mmol} / \mathrm{l}$, as well as postprandial glucose excursions, respectively. The postmeal relative areas under the CGM curve (AUCpp) for $1-4 \mathrm{~h}$ were calculated as a measure for postprandial excursion. The AUCpp was calculated as the glucose excursion relative to the baseline (premeal) value [16]. Postprandial glucose (PPG) peaks were defined as the highest glucose value within a 3-h window from meal start.

\section{Cost Calculation}

The monthly cost of Prandilin 25 or Humalog mix 25 of each patient was calculated by the following formula: sale price $(\mathrm{RMB} / 300 \mathrm{U}) \times$ dosage per day $\times 30 / 300$.

\section{Statistical Analysis}

CGM data were recorded and exported from the CGMS 3.0 software analysis system. Data were analyzed with the SPSS PASW Statistics 19 Package. Normally distributed and continuous variables were presented as mean \pm standard deviation (SD). Non-normally distributed variables were presented as median (interquartile range) and logarithmically transformed before analysis. The rates between the two groups were compared using the chi-square test. A two-way 
ANOVA was used to compare the hourly glucose concentrations between the two groups. The crossover analysis was based on a univariate general linear model, including the treatment regimen and period as fixed effects and patients as a random effect. $p<0.05$ was considered statistically significant.

\section{RESULTS}

\section{Baseline Characteristics of Patients}

Nine patients were excluded from this study; seven were from the Prandilin 25/Humalog Mix 25 group and two from the Humalog Mix 25/Prandilin 25 group. Among those patients, five were either unable to tolerate the $1 \mathrm{~g} /$ day dose of metformin or could not ensure their compliance with the energy intake instructions; four patients were excluded because of inadequate CGM data. Finally, there were 38 patients (23 males and 15 females, mean age
$55.21 \pm 10.83$ years, BMI $24.71 \pm 3.34 \mathrm{~kg} / \mathrm{m}^{2}$ ) in the Prandilin 25/Humalog Mix 25 group and 43 (27 males and 16 females, mean age $57.74 \pm 10.67$ years, BMI $24.57 \pm 2.69 \mathrm{~kg} / \mathrm{m}^{2}$ ) in the Humalog Mix 25/Prandilin 25 group. No statistical differences were shown between the two groups in terms of gender composition ratio, age, weight, BMI, fasting insulin, fasting C-peptide, fasting glucagon, and HOMA-IR as well as HOMA- $\beta$ (Table 1 ). The daily dose was $0.43 \pm 0.15 \mathrm{U} / \mathrm{kg} /$ day in the Prandilin $25 / \mathrm{Hu}-$ malog Mix 25 group and $0.45 \pm 0.18$ in the Humalog Mix 25/Prandilin 25 group, respectively $(p=0.304)$.

\section{Glycemic Variation Profiles}

The 24-h CGM glucose profiles of the patients of each treatment group are shown in Table 2. There were no significant differences in the 24hMBG, 24hSDBG, 24hMAGE, CV, MINBG, MAXBG, LABG, premeal glucose, and postprandial peak glucose after each meal between

Table 1 Baseline characteristics of patients

\begin{tabular}{lllll}
\hline & $\begin{array}{l}\text { Prandilin 25/Humalog } \\
\text { mix 25 group }\end{array}$ & $\begin{array}{l}\text { Humalog mix 25/ } \\
\text { Prandilin 25 group }\end{array}$ & $t$ value & $\boldsymbol{p}$ value \\
\hline Gender $(\mathrm{M} / \mathrm{F})$ & $38(23 / 15)$ & $43(27 / 16)$ & - & 0.834 \\
Age (years) & $55.21 \pm 10.83$ & $57.74 \pm 10.67$ & -1.059 & 0.293 \\
Weight $(\mathrm{kg})$ & $68.74 \pm 12.19$ & $67.79 \pm 11.64$ & 0.357 & 0.722 \\
BMI $\left(\mathrm{kg} / \mathrm{m}^{2}\right)$ & $24.71 \pm 3.34$ & $24.57 \pm 2.69$ & 0.211 & 0.833 \\
Insulin dosage (U/kg/day) & $0.43 \pm 0.15$ & $0.45 \pm 0.18$ & -0.358 & 0.721 \\
HbA1c (\%) & $10.99 \pm 1.42$ & $10.97 \pm 1.21$ & 0.050 & 0.960 \\
FBG (mmol/l) & $12.40 \pm 2.12$ & $12.73 \pm 3.07$ & -0.556 & 0.570 \\
Fasting insulin (mIU/l) & $5.98(3.74-9.45)$ & $6.62(4.50-9.45)$ & -0.852 & 0.397 \\
Fasting C-peptide (pmol/l) & $2.08 \pm 0.89$ & $2.18 \pm 0.63$ & -0.577 & 0.566 \\
Fasting glucagon (pmol/l) & $108.55 \pm 22.66$ & $113.46 \pm 33.82$ & -0.709 & 0.481 \\
HOMA- $\beta$ & $14.35(7.70-25.22)$ & $14.34(9.48-24.21)$ & -0.794 & 0.430 \\
HOMA-IR & $2.93(1.98-5.67)$ & $3.82(2.59-5.49)$ & -1.034 & 0.304 \\
\hline
\end{tabular}

Data are mean \pm SD for normally distributed and continuous variables and median (interquartile range) for non-normally distributed variables

$B M I$ body mass index, FBG fasting plasma glucose, HOMA- $\beta$ homeostasis model assessment- $\beta$, HOMA-IR homeostasis model assessment-IR 
Table 2 Effect of two kinds of insulin lispro 25 therapy with metformin on blood glucose variability

\begin{tabular}{lllll}
\hline Treatment & Prandilin 25 & Humalog mix 25 & $\boldsymbol{F}$ value & $\boldsymbol{p}$ value \\
\hline 24hMBG $(\mathrm{mmol} / \mathrm{l})$ & $7.43 \pm 1.10$ & $7.30 \pm 1.17$ & 0.680 & 0.411 \\
24hSDBG $(\mathrm{mmol} / \mathrm{l})$ & $1.74 \pm 0.75$ & $1.61 \pm 0.79$ & 0.862 & 0.355 \\
24hMAGE $(\mathrm{mmol} / \mathrm{l})$ & $4.14 \pm 1.84$ & $3.86 \pm 1.98$ & 0.839 & 0.361 \\
CV & $0.23 \pm 0.08$ & $0.22 \pm 0.09$ & 0.391 & 0.532 \\
MAXBG (mmol/l) & $12.25 \pm 2.85$ & $11.78 \pm 2.81$ & 1.144 & 0.287 \\
MINBG (mmol/l) & $4.45 \pm 1.01$ & $4.47 \pm 1.30$ & 0.001 & 0.973 \\
LAGE $(\mathrm{mmol} / \mathrm{l})$ & $7.80 \pm 2.98$ & $7.31 \pm 3.12$ & 1.009 & 0.317 \\
AUC $<3.9$ & $0.00(0.00,0.21)$ & $0.00(0.00,1.05)$ & 0.479 & 0.494 \\
$<3.9$ time $(\%)$ & $0.00(0.00,0.69)$ & $0.00(0.00,2.34)$ & 0.211 & 0.646 \\
AUC3.9-10 & $4595.34 \pm 1007.33$ & $4418.87 \pm 1140.89$ & 0.215 & 0.646 \\
$\geq 3.9$ and $\leq 10$ time $(\%)$ & $86.35 \pm 12.86$ & $87.10 \pm 13.33$ & 0.191 & 0.662 \\
AUC $>10$ & $101.90(0.00,497.85)$ & $64.20(0.00,400.05)$ & 0.351 & 0.558 \\
$>10$ time $(\%)$ & $7.46(0.00,17.36)$ & $7.12(0.00,15.10)$ & 0.448 & 0.504 \\
\hline
\end{tabular}

Data are mean \pm SD for normally distributed and continuous variables and median (interquartile range) for non-normally distributed variables

$M B G$ mean glucose concentration (mmol/l), $S D B G$ standard deviation of the MBG (mmol/l), $M A G E$ mean amplitude of glycemic excursion (mmol/l), $C V$ coefficient of variation, $M A X B G$ maximum blood glucose, MINBG minimum blood glucose, $L A G E$ large amplitude of glycemic excursion, $A U C<3.9$ decremental area over the curve of glucose concentrations $<3.9 \mathrm{mmol} / \mathrm{l}$ (mmol/l per day), $<3.9$ time percentage of the time spent on glucose concentrations $<3.9 \mathrm{mmol} / \mathrm{l}$, AUC3.9-10 incremental area under the curve of glucose concentrations between 3.9 and $10 \mathrm{mmol} / \mathrm{l}(\mathrm{mmol} / \mathrm{l}$ per day), $\geq 3.9$ and $\leq 10$ times percentage of the time spent on glucose concentrations between 3.9 and $10 \mathrm{mmol} / \mathrm{l}, A U C>10$ incremental area under the curve of glucose concentrations $>10.0 \mathrm{mmol} / \mathrm{l}(\mathrm{mmol} / \mathrm{l}$ per day), $>10$ times percentage of time spent on glucose concentrations above $10.0 \mathrm{mmol} / \mathrm{l}$

patients with Prandilin 25 treatment (Prandilin group) and those with Humalog Mix 25 treatment (Humalog group). Moreover, the AUCs of blood glucose below $3.9 \mathrm{mmol} / \mathrm{l}$, between 3.9 and $10.0 \mathrm{mmol} / \mathrm{l}$, and above $10.0 \mathrm{mmol} / \mathrm{l}$ were all similar between groups (Table 3); the percentages of time when blood glucose $<3.9 \mathrm{mmol} / \mathrm{l}$, between 3.9 and $10.0 \mathrm{mmol} / \mathrm{l}$, and $>10.0 \mathrm{mmol} / \mathrm{l}$ were also similar between the two groups' patients (Table 2).

We further analyzed the postprandial glucose excursions of each patient. No significant differences could be found in AUCpp value 1-4 $\mathrm{h}$ for breakfast, lunch, and dinner between the two groups, respectively. The average time to peak for each meal in the Prandilin group was also similar to that in the Humalog group (Table 3).

The average glucose concentration per hour carrying 24-h period was similar between the Prandilin group and Humalog group ( $p>0.05$, Fig. 1).

\section{Hypoglycemic Episodes}

There were no severe hypoglycemic episodes, defined as an event requiring the assistance of another person or other resuscitative treatments in both groups. In total, the number of hypoglycemia events $(<3.9 \mathrm{mmol} / \mathrm{l})$ was 11 in the Prandilin group and 17 in the Humalog group, respectively. No statistical differences could be 
Table 3 Effect of Prandilin 25 or Humalog mix 25 therapy with metformin on postprandial blood glucose fluctuation in new diagnosis T2DM patients

\begin{tabular}{|c|c|c|c|c|}
\hline Treatment & Prandilin 25 & Humalog mix 25 & $F$ value & $p$ value \\
\hline \multicolumn{5}{|l|}{ Breakfast } \\
\hline $1 \mathrm{~h}$ before meal MBG & $7.05 \pm 1.27$ & $6.79 \pm 1.28$ & 2.542 & 0.115 \\
\hline Premeal (mmol/l) & $7.17 \pm 1.39$ & $6.89 \pm 1.27$ & 1.919 & 0.168 \\
\hline PPG peak $(\mathrm{mmol} / \mathrm{l})$ & $11.16 \pm 2.92$ & $11.14 \pm 2.70$ & 0.011 & 0.917 \\
\hline Peak height $(\mathrm{mmol} / \mathrm{l})$ & $3.99 \pm 2.62$ & $4.25 \pm 2.61$ & 0.348 & 0.556 \\
\hline Time to peak (min) & $90.09 \pm 34.16$ & $85.85 \pm 29.06$ & 0.711 & 0.400 \\
\hline \multicolumn{5}{|c|}{ AUCpp CGM $(\mathrm{min} / \mathrm{mmol} / \mathrm{l})$} \\
\hline $1 \mathrm{~h}$ & $75.20 \pm 65.97$ & $76.87 \pm 57.22$ & 0.041 & 0.840 \\
\hline $2 \mathrm{~h}$ & $243.64 \pm 186.56$ & $268.97 \pm 184.23$ & 1.510 & 0.223 \\
\hline $3 \mathrm{~h}$ & $396.48 \pm 296.97$ & $412.63 \pm 294.37$ & 0.149 & 0.701 \\
\hline $4 \mathrm{~h}$ & $465.93 \pm 365.59$ & $462.48 \pm 338.01$ & 0.038 & 0.846 \\
\hline \multicolumn{5}{|l|}{ Lunch } \\
\hline $1 \mathrm{~h}$ before meal MBG & $7.45 \pm 2.15$ & $7.01 \pm 1.92$ & 2.641 & 0.108 \\
\hline Premeal (mmol/l) & $6.98 \pm 2.11$ & $6.43 \pm 1.81$ & 3.267 & 0.073 \\
\hline PPG peak $(\mathrm{mmol} / \mathrm{l})$ & $8.72 \pm 2.02$ & $8.56 \pm 2.17$ & 0.273 & 0.602 \\
\hline Peak height $(\mathrm{mmol} / \mathrm{l})$ & $1.70(0.53,2.70)$ & $2.10(0.60,3.00)$ & 1.522 & 0.219 \\
\hline Time to peak (min) & $76.30 \pm 35.48$ & $76.37 \pm 25.97$ & 0.007 & 0.934 \\
\hline \multicolumn{5}{|c|}{ AUCpp CGM $(\mathrm{min} / \mathrm{mmol} / \mathrm{l})$} \\
\hline $1 \mathrm{~h}$ & $24.60(3.62,58.47)$ & $32.55(4.17,65.70)$ & 2.546 & 0.116 \\
\hline $2 \mathrm{~h}$ & $66.00(22.12,153.35)$ & $103.40(15.02,191.60)$ & 1.586 & 0.212 \\
\hline $3 \mathrm{~h}$ & $102.75(27.83,286.77)$ & $132.75(25.60,279.75)$ & 0.941 & 0.335 \\
\hline $4 \mathrm{~h}$ & $126.55(34.31,417.75)$ & $177.75(37.12,382.87)$ & 0.268 & 0.202 \\
\hline \multicolumn{5}{|l|}{ Dinner } \\
\hline $1 \mathrm{~h}$ before meal MBG & $7.02 \pm 1.81$ & $7.38 \pm 2.18$ & 1.571 & 0.214 \\
\hline Premeal (mmol/l) & $6.96 \pm 1.78$ & $7.29 \pm 1.97$ & 1.152 & 0.285 \\
\hline PPG peak $(\mathrm{mmol} / \mathrm{l})$ & $9.42 \pm 2.23$ & $9.39 \pm 2.31$ & 0.010 & 0.921 \\
\hline Peak height $(\mathrm{mmol} / \mathrm{l})$ & $2.50(1.10,3.30)$ & $1.90(1.00,3.00)$ & 1.309 & 0.254 \\
\hline Time to peak (min) & $66.47 \pm 30.50$ & $65.50 \pm 27.70$ & 0.049 & 0.825 \\
\hline \multicolumn{5}{|c|}{ AUCpp CGM $(\mathrm{min} / \mathrm{mmol} / \mathrm{l})$} \\
\hline $1 \mathrm{~h}$ & $44.20(17.37,80.87)$ & $44.75(25.18,72.75)$ & 0.655 & 0.421 \\
\hline $2 \mathrm{~h}$ & $120.75(34.11,196.20)$ & $110.00(61.87,193.75)$ & 1.157 & 0.286 \\
\hline $3 \mathrm{~h}$ & $169.00(54.75,263.87)$ & $160.25(92.42,246.52)$ & 0.036 & 0.851 \\
\hline
\end{tabular}


Table 3 continued

\begin{tabular}{lllll}
\hline Treatment & Prandilin 25 & Humalog mix 25 & $\boldsymbol{F}$ value & $\boldsymbol{p}$ value \\
\hline $4 \mathrm{~h}$ & $197.40(80.37,332.30)$ & $181.95(92.67,312.42)$ & 0.077 & 0.782 \\
\hline
\end{tabular}

Data are mean \pm SD for normally distributed and continuous variables and median (interquartile range) for non-normally distributed variables

$1 \mathrm{~h}$ before meal $M B G$ mean 1-h pre-prandial blood glucose, PPG postprandial glucose, peak height calculated as (PPG peak - premeal glucose), $A U C P p C G M$ postmeal relative areas under the continuous glucose monitoring curve

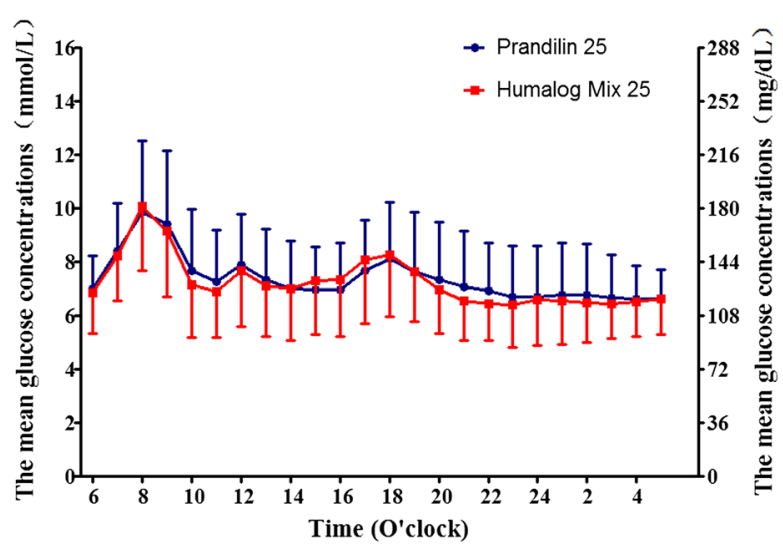

Fig. 1 The glucose concentration per hour for 24-h by CGM in the Prandilin 25 treatment group (Prandilin 25) and Humalog Mix 25 treatment group (Humalog Mix 25). The hourly glucose concentrations are calculated from CGM. Data are presented as mean $\pm \mathrm{SD}$

found between the two groups by chi-square analysis (chi square $=1.00, p=0.317$ ). The declined AUC and time when blood glucose $<3.9 \mathrm{mmol} / \mathrm{l}$ as detected by CGM were not significantly different between the two groups.

\section{Economic Value}

Using the same dose, the cost of Prandilin 25 was $\mathrm{RMB} 185.77 \pm 55.92 /$ month, which was significantly lower than that of Humalog Mix 25 (RMB $217.68 \pm 72.81 /$ month, $p<0.05$ ).

\section{DISCUSSION}

This short-term study demonstrated that Prandilin 25 has non-inferior efficacy in clinical practice compared with Humalog Mix 25 not only in reducing hyperglycemia but also in controlling glucose variability, as well as managing hypoglycemic episodes, based on different parameters calculated from CMG data. Meanwhile, considering the significant difference in cost, Prandilin 25 may be a much more cost-effective insulin lispro 25 for T2DM glucose control.

It is well established that there are significant associations between cardiovascular complications and glycemic profiles, such as glycosylated hemoglobin A1c (HbA1c) and fasting and postprandial hyperglycemia. HbA1c has been considered the gold standard assessment of longterm overall glycemic control during the past decades. Reduction of the HbA1c value in patients with diabetes results in significant reductions in the risk of death, myocardial infarction, and any end point related to diabetes $[17,18]$. However, accumulating evidence indicates that the GV, which manifests principally as postprandial glycemic spikes and minor (or asymptomatic) hypoglycemia, has been recognized as an important independent risk factor for diabetic complications even at a similar HbA1c level [19-22]. It was suggested that GV could induce oxidative stress and endothelial dysfunction, which may eventually contribute to the development and progression of micro- and macrovascular complications [22]. Except for HbA1c, therefore, GV should also be treated as another pivotal goal of blood glucose control. Compared with the structured sevenpoint self-monitoring of blood glucose, CGMS can monitor the subcutaneous interstitial fluid glucose level automatically every $5 \mathrm{~min}$ and thus provide dynamic changes of blood glucose for no less than $72 \mathrm{~h}$ to show more comprehensively and accurately the blood glucose excursion throughout the day. Hence, the 
CGMS is a reliable and useful tool to measure the GV of patients with diabetes mellitus $[23,24]$. In the present study, we used CGMS to compare the efficacy, safety, risk of hypoglycemia, and glucose excursion profile of two low premixed insulin lispro 25s, Prandilin 25 and Humalog mix 25, in T2DM patients. It had been declared that Prandilin 25 has the same active ingredient structure and similar bioequivalent pharmacodynamic and pharmacokinetic characteristics compared with Humalog mix 25 , but a head-to-head study is still needed to compare the clinical efficacy of these two drugs in diabetes mellitus patients. Our study demonstrated that both Prandilin 25 and Humalog mix 25 have the same efficacy in the management of hyperglycemia as evidenced by $24 \mathrm{hMBG}$ and pre- and post-prandial blood glucose for each meal at the same dose. Moreover, they showed similar effects on controlling GV, such as 24hMAGE, 24hSDBG, CV, and LAGE (Table 2).

Postprandial hyperglycemia control is important for achieving overall glycemic control. Moreover, postprandial glucose has been suggested to be an independent risk factor for diverse complications; in addition to cardiovascular disease and microvascular events, elevated PPG has been associated with such conditions as cognitive dysfunction and cancer [25-27]. Thus, it is necessary to treat postprandial glucose control as an important strategy in the comprehensive management plan of individuals with diabetes. As shown in Table 3 , there were no statistical differences between the two groups in terms of postprandial Max BG, time to peak, and AUCpp 1-4 h for each meal, indicating Prandilin 25 has the same efficacy on control of postprandial glucose excursions compared with Humalog mix 25.

Hypoglycemia and fear of hypoglycemia are the other major barriers to using anti-diabetes medicines. Hypoglycemia has been strongly associated with increased risk of cardiovascular events and death $[28,29]$. Using CGMS, we were able to identify asymptomatic or nocturnal hypoglycemia during insulin lipro 25 treatment. The frequency of hypoglycemic episodes (blood glucose $<3.9 \mathrm{mmol} / \mathrm{l}$ ) was similar between the Prandilin group and Humalog group. Therefore, in conclusion, the same dose of Prandilin 25 and Humalog mix 25 has the same clinical efficacy on management of hyperglycemia and controlling glucose excursion as well as risk of hypoglycemia.

Diabetes is not only a global health problem because of its effect on mortality and morbidity and quality of life, but also a major problem for national economies. Since diabetes is a long life chronic disease, with a tremendous number of diabetic patients worldwide, the medical cost for the management of this condition and its complications is a heavy economic burden for individuals and countries. Our study further demonstrated that Prandilin 25 is a much more cost-effective drug compared with Humalog mix 25. The cost of Prandilin 25 is only $85 \%$ of Humalog mix 25 every month. The 15\% reduction of drug cost will have a significantly positive impact not only on patients with T2DM but also on the economic development of nations. Therefore, Prandilin 25, being a costeffective insulin lispro 25 , offers a better option for T2DM treatment.

There were still limitations in the present study. First, this was a short-term clinical study. It was impossible to assess whether there were differences in the immunogenicity and antibody titer against the two drugs after long-term usage or not. Second, we did not test the patient's preference and performance of the injection pen designed for Prandilin 25 and Humalog mix 25. Those possible differences might in turn affect the clinical efficacy and safety of the two drugs.

\section{CONCLUSIONS}

In summary, compared with Humalog mix 25, Prandilin 25 has similar clinical efficacy on $24 \mathrm{~h}$ blood glucose fluctuation, average blood glucose, fasting blood glucose and postprandial glucose excursions as well as the incidence of hypoglycemia in newly diagnosed T2DM patients. However, considering the valuable difference in the cost of the two drugs, Prandilin 25 would be a much more cost-effective medication for the management of T2DM. 


\section{ACKNOWLEDGEMENTS}

The authors thank the patients participating in this study. We would also like to thank all of the staff in the participating hospitals.

Funding. The study was supported by funds from the Scientific and Technological Development Program of Jiangsu Province of China (BL2014010). Article processing charges were funded by the authors.

Authorship. All named authors meet the International Committee of Medical Journal Editors (ICMJE) criteria for authorship for this manuscript, take responsibility for the integrity of the work as a whole, and gave final approval for the version to be published.

Author Contributions. Jian-hua Ma, Jian $\mathrm{Zhu}$, and Lei Ye contributed to the conception and design of the study. Yong Luo, Xue-qin Wang, Wen-ji Ni, Bo Ding, and Xiang-hong Xu contributed to the conduct/data collection. Yong Luo, Xue-qin Wang, and Jian Zhu contributed to data analysis. Jian Zhu and Yong Luo contributed to manuscript writing. Jian-hua Ma and Jian Zhu provided final approval of the manuscript.

Disclosures. Yong Luo, Xue-qin Wang, Wen-ji Ni, BO Ding, Xiang-hong $\mathrm{Xu}$, Lei Ye, Jian-hua $\mathrm{Ma}$, and Jian $\mathrm{Zhu}$ have nothing to disclose.

Compliance with Ethics Guidelines. All procedures followed were in accordance with the Helsinki Declaration of 1964, as revised in 2013. Informed consent was obtained from all patients for being included in the study.

Data Availability. The data sets generated during and/or analyzed during the current study are not publicly available but are available from the corresponding author on reasonable request.

Open Access. This article is distributed under the terms of the Creative Commons Attribution-NonCommercial 4.0 International
License (http://creativecommons.org/licenses/ by-nc/4.0/), which permits any noncommercial use, distribution, and reproduction in any medium, provided you give appropriate credit to the original author(s) and the source, provide a link to the Creative Commons license, and indicate if changes were made.

\section{REFERENCES}

1. Cho NH, Shaw JE, Karuranga S, Huang Y, da Rocha Fernandes JD, Ohlrogge AW, et al. IDF Diabetes Atlas: global estimates of diabetes prevalence for 2017 and projections for 2045. Diabetes Res Clin Pract. 2018;138:271-81.

2. Danaei G, Lawes CM, Vander Hoorn S, Murray CJ, Ezzati M. Global and regional mortality from ischaemic heart disease and stroke attributable to higher-than-optimum blood glucose concentration: comparative risk assessment. Lancet (Lond Engl). 2006;368:1651-9.

3. Zhang P, Gregg E. Global economic burden of diabetes and its implications. Lancet Diabetes Endocrinol. 2017;5:404-5.

4. Bommer C, Heesemann E, Sagalova V, ManneGoehler J, Atun R, Barnighausen T, et al. The global economic burden of diabetes in adults aged 20-79 years: a cost-of-illness study. Lancet Diabetes Endocrinol. 2017;5:423-30.

5. Bommer C, Sagalova V, Heesemann E, ManneGoehler J, Atun R, Barnighausen T, et al. Global economic burden of diabetes in adults: projections from 2015 to 2030. Diabetes Care. 2018;41:963-70.

6. Wang W, McGreevey WP, Fu C, Zhan S, Luan R, Chen W, et al. Type 2 diabetes mellitus in China: a preventable economic burden. Am J Manag Care. 2009;15:593-601.

7. Jan S, Laba T-L, Essue BM, Gheorghe A, Muhunthan $\mathrm{J}$, Engelgau M, et al. Action to address the household economic burden of non-communicable diseases. Lancet. 2018;391:2047-58.

8. Weng J, Ji L, Jia W, Lu J, Zhou Z, Zou D, et al. Standards of care for type 2 diabetes in China. Diabetes Metab Res Rev. 2016;32:442-58.

9. Müller N, Frank T, Kloos C, Lehmann T, Wolf G, Müller UA. Randomized crossover study to examine the necessity of an injection-to-meal interval in patients with type 2 diabetes and human insulin. Diabetes Care. 2013;36:1865-9. 
10. Guo XH, Yuan L, Lou QQ, Shen L, Sun ZL, Zhao F, et al. Chinese Diabetes Education Status Survey Study G: a nationwide survey of diabetes education, self-management and glycemic control in patients with type 2 diabetes in China. Chin Med J (Engl). 2012;125:4175-80.

11. El Naggar N, Kalra S. Switching from biphasic human insulin to premix insulin analogs: a review of the evidence regarding quality of life and adherence to medication in type 2 diabetes mellitus. Adv Ther. 2017;33:2091-109.

12. Sheu WHH, Ji L, Lee WJ, Jabbar A, Han JH, Lew T. Efficacy and safety of premixed insulin analogs in Asian patients with type 2 diabetes: a systematic review. J Diabetes Investig. 2017;8:518-34.

13. Elizarova S, Galstyan GR, Wolffenbuttel BHR. Role of premixed insulin analogues in the treatment of patients with type 2 diabetes mellitus: a narrative review. J Diabetes. 2014;6:100-10.

14. Li W, Ping F, Xu L, Zhou M, Li H, Dong Y, et al. Effects of insulin lispro mix 25 and insulin lispro mix 50 on postprandial glucose excursion in patients with type 2 diabetes: a prospective, openlabel, randomized clinical trial. Diabetes Ther. 2018;9:699-711.

15. Li FF, Jiang L, Fu L, Zhu HH, Zhou P, Zhang D, et al. Exenatide add-on to continuous subcutaneous insulin infusion therapy reduces bolus insulin doses in patients with type 2 diabetes: a randomized, controlled, open-label trial. Diabetes Ther. 2017;8:177-87.

16. Cichosz SL, Fleischer J, Hoeyem P, Laugesen E, Poulsen PL, Christiansen JS, et al. Assessment of postprandial glucose excursions throughout the day in newly diagnosed type 2 diabetes. Diabetes Technol Ther. 2013;15:78-83.

17. Kirkman MS, Mahmud H, Korytkowski MT. Intensive blood glucose control and vascular outcomes in patients with type 2 diabetes mellitus. Endocrinol Metab Clin N Am. 2018;47:81-96.

18. Wong MG, Perkovic V, Chalmers J, Woodward M, Li Q, Cooper ME, et al. Long-term benefits of intensive glucose control for preventing end-stage kidney disease: ADVANCE-ON. Diabetes Care. 2016;39:694-700.
19. Ceriello A, Ihnat MA. 'Glycaemic variability': a new therapeutic challenge in diabetes and the critical care setting. Diabetic Med. 2010;27:862-7.

20. Hirsch IB. Glycemic variability and diabetes complications: does it matter? Of course it does! Diabetes Care. 2015;38:1610-4.

21. Brownlee $M$, Hirsch IB. Glycemic variability: a hemoglobin A1c-independent risk factor for diabetic complications. JAMA. 2006;295:1707-8.

22. Costantino S, Paneni F, Battista R, Castello L, Capretti G, Chiandotto S, et al. Impact of glycemic variability on chromatin remodeling, oxidative stress, and endothelial dysfunction in patients with type 2 diabetes and with target HbA1c levels. Diabetes. 2017;66:2472-82.

23. Vashist SK. Continuous glucose monitoring systems: a review. Diagnostics (Basel Switz). 2013;3:385-412.

24. Li FF, Shen Y, Sun R, Zhang DF, Jin X, Zhai XF, et al. Effects of vildagliptin add-on insulin therapy on nocturnal glycemic variations in uncontrolled type 2 diabetes. Diabetes Ther. 2017;8:1111-22.

25. Kitasato L, Tojo T, Hatakeyama Y, Kameda R, Hashikata T, Yamaoka-Tojo M. Postprandial hyperglycemia and endothelial function in type 2 diabetes: focus on mitiglinide. Cardiovasc Diabetol. 2012;11:79.

26. Low Wang CC, Hess CN, Hiatt WR, Goldfine AB. Atherosclerotic cardiovascular disease and heart failure in type 2 diabetes-mechanisms, management, and clinical considerations. Circulation. 2016;133:2459-502.

27. Mah E, Bruno RS. Postprandial hyperglycemia on vascular endothelial function: mechanisms and consequences. Nutr Res (N Y NY). 2012;32:727-40.

28. Seaquist ER, Anderson J, Childs B, Cryer P, DagogoJack S, Fish L, et al. Hypoglycemia and diabetes: a report of a workgroup of the American Diabetes Association and The Endocrine Society. Diabetes Care. 2013;36:1384-95.

29. Cryer PE. The barrier of hypoglycemia in diabetes. Diabetes. 2008;57:3169-76. 